\title{
New drugs for medullary thyroid cancer: new promises?
}

\author{
Christine Spitzweg', John C Morris² and Keith C Bible ${ }^{3}$ \\ 1Department of Internal Medicine II - Campus Grosshadern, University Hospital of Munich, \\ Ludwig-Maximilians-University Munich, Munich, Germany \\ 2Division of Endocrinology and Metabolism, Mayo Clinic, Rochester, Minnesota, USA \\ 3Division of Medical Oncology, Mayo Clinic, Rochester, Minnesota, USA
}

Correspondence should be addressed to C Spitzweg Email Christine.Spitzweg@med. uni-muenchen.de

\begin{abstract}
Medullary thyroid cancer (MTC) is a rare tumor arising from the calcitonin-producing parafollicular $\mathrm{C}$ cells of the thyroid gland, occurring either sporadically or alternatively in a hereditary form based on germline RET mutations in approximately one-third of cases. Historically, patients with advanced, metastasized MTC have had a poor prognosis, partly due to limited response to conventional chemotherapy and radiation therapy. In the past decade, however, considerable progress has been made in identifying key genetic alterations and dysregulated signaling pathways paving the way for the evaluation of a series of multitargeted kinase inhibitors that have started to meaningfully impact clinical practice. Two drugs, vandetanib and cabozantinib, are now approved in the US and EU for use in advanced, progressive MTC, with additional targeted agents also showing promise or awaiting results from clinical trials. However, the potential for toxicities with significant reduction in quality of life and lack of curative outcomes has to be carefully weighed against potential for benefit. Despite significant PFS prolongation observed in randomized clinical trials, most patients even with metastatic disease enjoy indolent courses with slow progression observed over years, wherein watchful waiting is still the preferred strategy. As advanced, progressive MTC is a rare and complex disease, a multidisciplinary approach centered in specialized centers providing interdisciplinary expertise in the individualization of available therapeutic options is preferred. In this review, we summarize current concepts of the molecular pathogenesis of advanced MTC and discuss results from clinical trials of targeted agents and also cytotoxic chemotherapy in the context of clinical implications and future perspectives.
\end{abstract}

\section{Key Words \\ - medullary thyroid cancer \\ - multitargeted kinase inhibitors \\ - cytotoxic chemotherapy \\ - personalized therapy}

Endocrine-Related Cancer (2016) 23, R287-R297

\section{Introduction}

Medullary thyroid cancer (MTC) is a rare tumor (3-5\% of all thyroid cancers) arising from the calcitonin-producing parafollicular C cells of the thyroid gland (Wells et al. 2015, Hadoux et al. 2016). MTC occurs either sporadically or (in approximately one-third of cases) in a hereditary form as a component of the type 2 multiple endocrine neoplasia (MEN) syndromes MEN2A and 2B and the related syndrome familial MTC (FMTC) associated with germline RET (rearranged during transfection) mutations (Wells et al. 2015, Hadoux et al. 2016). The RET protooncogene is located on chromosome 10q11.2, encodes a single-pass transmembrane tyrosine kinase receptor, and is known to play a central role in the tumorigenesis of sporadic and hereditary MTC (Wells et al. 2015, Hadoux et al. 2016).

Published by Bioscientifica Ltd. 
While RET germline mutations can be detected in almost $100 \%$ of hereditary MTC cases, sporadic MTCs reveal somatic RET mutations in $50-60 \%$ of cases (Wells et al. 2015, Hadoux et al. 2016).

In contrast to differentiated thyroid cancer (DTC), MTCs do not participate in iodide transport and metabolism of the thyroid gland and therefore are not amenable to radioiodine therapy. Adequate primary surgery, i.e. total en bloc thyroidectomy including riskadapted compartment-oriented lymph node dissection, remains the only curative therapeutic option, when performed at a sufficiently early stage and in experienced surgical hands. The overall prognosis of patients with MTC is relatively good, with a 15-year survival rate of $85 \%$. Important prognostic factors are age and stage of disease at the time of diagnosis. Ten-year survival rate is $96 \%$ in patients with localized disease, compared with $76 \%$ in patients with regional disease; median overall survival is only 3 years in patients with distant metastases (Cabanillas et al. 2014, Wells et al. 2015, Hadoux et al. 2016). However, most patients with metastatic disease still have an indolent course with stable disease or slow progression over years associated with good quality of life. Treatment of metastatic disease includes local treatment (e.g. surgery, stereotactic external beam radiotherapy, thermoablation, and chemo- or radioembolization). In many cases, watchful waiting is the preferred strategy before committing to systemic treatment even in patients with disseminated disease, unless significantly progressive, imminently threatening, and/or symptomatic.
In the past decade, considerable progress has been made in delineating the molecular pathogenesis of MTC through identification of genetic alterations and dysregulated signaling pathways (Fig. 1). Key therapeutic molecular targets have been identified that allowed the evaluation of a series of multitargeted kinase inhibitors that have begun to meaningfully impact clinical practice in patients with sufficiently threatening disease to require systemic therapy (Table 1 ).

\section{Molecular pathogenesis of medullary thyroid cancer}

Understanding of candidate initiating and driving events in oncogenic transformation of thyroidal $\mathrm{C}$ cells has been facilitated by the discovery of activating germline mutations of the RET gene in the early 1990s as the genetic basis for hereditary forms of MTC (Wells et al. 2015). RET is located on chromosomal band 10q11.2 and encodes a single-pass transmembrane receptor tyrosine kinase. The RET protein has an extracellular ligand-binding domain composed of a cadherin-like region, and a highly conserved cysteine-rich domain. The intracellular region is composed of two tyrosine kinase domains. Upon ligand binding, the extracellular cysteine-rich domain facilitates receptor dimerization leading to autophosphorylation and tyrosine kinase activation triggering parallel downstream signaling pathway activation including RAS/RAF/MAPK, PI3K/AKT, and JAK-STAT pathways (Mulligan 2014). More than 80 different germline RET mutations have been

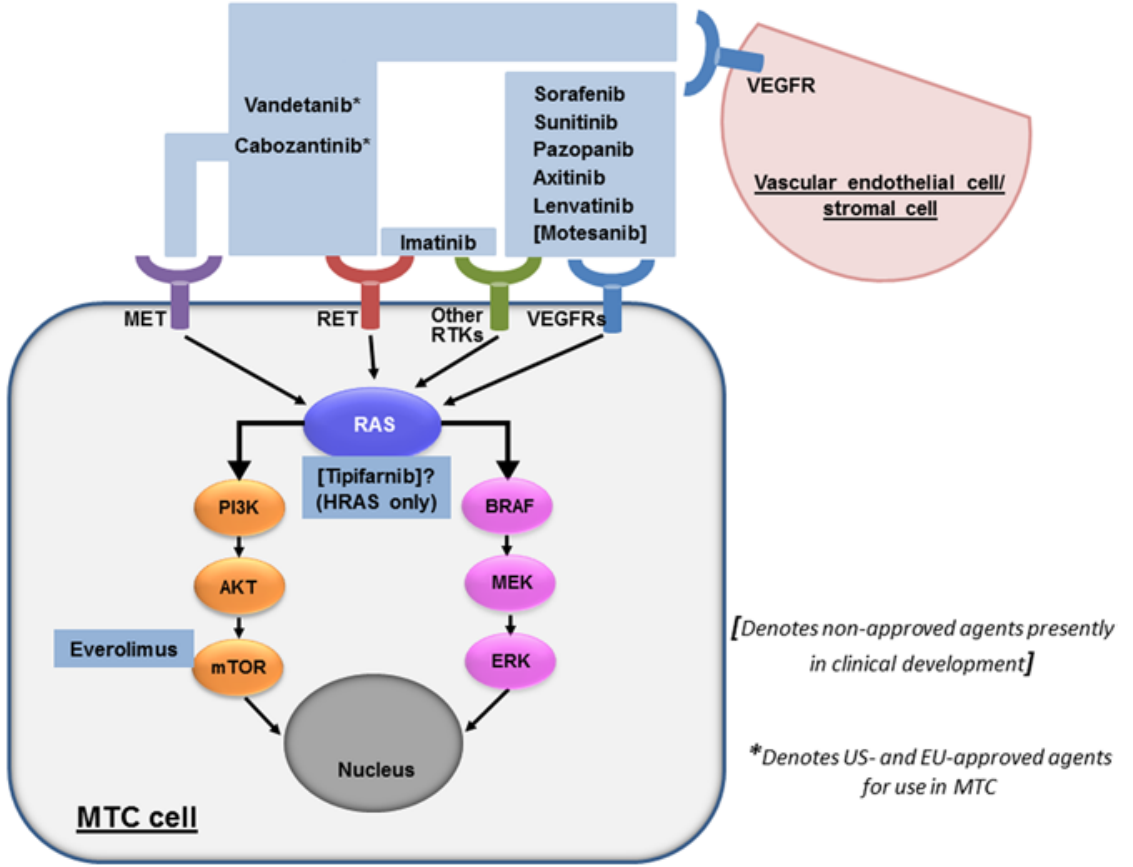

Figure 1

Targeted therapies evaluated in clinical trials for advanced MTC based on identification of central signaling pathways [denotes non-approved agents presently in clinical development]. *Denotes US- and EU-approved agents for use in MTC. 
Table 1 Targeted therapies in medullary thyroid cancer: investigational agents and results of clinical trials.

\begin{tabular}{|c|c|c|c|c|c|c|}
\hline Reference & Agent(s) & Main targets & Patients $(n)$ & PR (\%) & SD (\%) & PFS \\
\hline Wells et al. (2010) & $\begin{array}{l}\text { Vandetanib } \\
\text { phase } 2\end{array}$ & RET, VEGFR, EGFR & 30 & 20 & 53 & 27.9 months \\
\hline Robinson et al. (2010) & $\begin{array}{l}\text { Vandetanib } \\
\text { phase } 2\end{array}$ & & 19 & 16 & 53 & \\
\hline Fox et al. (2013) & $\begin{array}{l}\text { Vandetanib } \\
\text { phase } 1 / 2\end{array}$ & & 16 & 47 & & \\
\hline *Wells et al. (2012) & $\begin{array}{l}\text { Vandetanib } \\
\text { phase } 3\end{array}$ & & 331 & 45 & 42 & 30.5 months \\
\hline Kurzrock et al. (2011) & $\begin{array}{l}\text { Cabozantinib } \\
\text { phase } 1\end{array}$ & VEGFR, MET, RET & 37 & 29 & 40.5 & \\
\hline *Elisei et al. (2013) & $\begin{array}{l}\text { Cabozantinib } \\
\text { phase } 3\end{array}$ & & 330 & 28 & & 11.2 months \\
\hline Lam et al. (2010) & $\begin{array}{l}\text { Sorafenib } \\
\text { phase } 2\end{array}$ & $\begin{array}{l}\text { VEGFR, PDGFR, RET, FGFR, } \\
\text { c-KIT, BRAF }\end{array}$ & 16 & 6.3 & 87.5 & 17.9 months \\
\hline Ahmed et al. (2011) & $\begin{array}{l}\text { Sorafenib } \\
\text { phase } 2\end{array}$ & & 15 & 25 (12 months) & & \\
\hline Frank-Raue et al. (2011) & Sorafenib & & 5 & 40 & 40 & \\
\hline Castroneves et al. (2016) & $\begin{array}{l}\text { Sorafenib } \\
\text { retrospective }\end{array}$ & & 12 & 0 & 83.3 & 9 months \\
\hline Carr et al. (2010) & $\begin{array}{l}\text { Sunitinib } \\
\text { phase } 2\end{array}$ & VEGFR, PDGFR, c-KIT, RET & 6 & 50 & 33.3 & \\
\hline De Souza et al. (2010) & $\begin{array}{l}\text { Sunitinib } \\
\text { phase } 2\end{array}$ & & 23 & 35 & 57 & \\
\hline Ravaud et al. (2010) & $\begin{array}{l}\text { Sunitinib } \\
\text { phase } 2\end{array}$ & & 15 & 13.3 & 46.7 & \\
\hline Bible et al. (2014) & $\begin{array}{l}\text { Pazopanib } \\
\text { phase } 2\end{array}$ & $\begin{array}{l}\text { VEGFR, PDGFR, C-KIT, FGRF, } \\
\text { RET }\end{array}$ & 35 & 14.3 & & 9.4 months \\
\hline Cohen et al. (2008) & $\begin{array}{r}\text { Axitinib } \\
\text { phase } 2\end{array}$ & VEGFR & 11 & 18 & 27.3 & \\
\hline Locati et al. (2014) & $\begin{array}{r}\text { Axitinib } \\
\text { phase } 2\end{array}$ & & 6 & 0 & 83 & \\
\hline Schlumberger et al. (2016) & $\begin{array}{l}\text { Lenvatinib } \\
\text { phase } 2\end{array}$ & $\begin{array}{l}\text { VEGFR, FGFR, RET, c-KIT, } \\
\text { PDGFR }\end{array}$ & 59 & 36 & 44 & 9 months \\
\hline Schlumberger et al. (2009) & $\begin{array}{l}\text { [Motesanib] } \\
\text { phase } 2\end{array}$ & VEGFR, PDGFR, c-KIT & 91 & 2 & 48 & 12 months \\
\hline De Groot et al. (2007) & $\begin{array}{l}\text { Imatinib } \\
\text { phase } 2\end{array}$ & Bcr-Abl, PDGFR c-KIT, RET & 15 & 0 & 27 & \\
\hline Frank-Raue et al. (2007) & Imatinib & & 9 & & 66.7 & 6 months \\
\hline Schneider et al. (2015) & $\begin{array}{l}\text { Everolimus } \\
\text { phase } 2\end{array}$ & mTOR & 7 & & 71 & 33 weeks \\
\hline Lim et al. (2013) & $\begin{array}{l}\text { Everolimus } \\
\text { phase } 2\end{array}$ & & 9 & & 100 & \\
\hline Sherman et al. (2015) & $\begin{array}{l}\text { Everolimus }+ \\
\text { Sorafenib } \\
\text { phase } 2\end{array}$ & $\begin{array}{l}\text { mTOR } \\
\text { VEGFR, PDGFR, RET } \\
\text { FGFR, c-KIT, BRAF }\end{array}$ & 10 & 40 & 40 & \\
\hline Hong et al. (2011) & $\begin{array}{l}\text { [Tipifarnib] }+ \\
\text { Sorafenib } \\
\text { phase } 1\end{array}$ & $\begin{array}{l}\text { HRAS farnelyzation } \\
\text { VEGFR, PDGFR, RET } \\
\text { FGFR, C-KIT, BRAF }\end{array}$ & 13 & 38 & 31 & \\
\hline
\end{tabular}

*Denotes registration trial supporting US- and EU-approved agents for use in MTC.

PR, partial response; SD, stable disease; PFS, progression-free survival. [Denotes investigational agents not yet subject to regulatory approval for any indication].

identified in hereditary MTC. Most are singe-nucleotide missense mutations resulting in constitutive activation of the RET tyrosine kinase (Wells et al. 2015).

In contrast to hereditary MTC, oncogenic mechanisms underlying the pathogenesis of sporadic MTC are less well understood. In sporadic MTC, somatic RET mutations are identified in $50-60 \%$ of cases. The most common somatic mutation in sporadic MTC is the RET M918T mutation that causes most cases of MEN2B and seems associated with more aggressive disease course (Wells et al. 2015). Studies that have tried to analyze the correlation of clinicopathological features with somatic RET mutations 
suggest that patients with mutations in RET exons 15 and 16 have highest risk of aggressive MTC (Moura et al. 2015). Some data also suggest that RET mutations in sporadic disease are not driver mutations, but rather seem to play a role in disease progression (Chernock \& Hagemann 2015). RET mutations show significant mutational heterogeneity, and are often found only in subpopulations of tumor cells; moreover, RET mutational status can differ between primary tumor and metastases. Interestingly, it was recently reported that the expression of tyrosine kinase inhibitor (TKI) target proteins in MTC is influenced by RET mutation status (Rodriguez-Antona et al. 2013). So far, only a few non-RET molecular alterations have been detected in MTC, including primarily HRAS and KRAS mutations, as well as BRAF mutations (0-7\%) (Moura et al. 2015). In a recent study, also very few mutations in genes encoding KIT, MLH1, STK11, and MET were reported (Ji et al. 2015). In addition, ALK rearrangements were found in 2 of 98 screened cases (Ji et al. 2015). RAS mutations seem to be mutually exclusive with RET mutations and have been reported in different series to be present in approximately $0-81.3 \%$ of RET wild-type sporadic MTC (Moura et al. 2015). Several studies suggest that MTCs harboring a RAS mutation show less aggressive behavior (Moura et al. 2015). Based on the discovery of RAS mutations in a significant number of MTCs, RAS has emerged as another potential molecular target for novel personalized treatment strategies. Mancikova and coworkers investigated the influence of RAS mutations on expression levels of key TKI targets, including EGFR, KIT, MET, PDGFR, VEGF, and VEGFR1-3, in a series of 84 MTC tumors (14 RAS-positive tumors, 18 RETM918T-positive tumors, 24 RETC634-positive tumors). RAS-mutated tumors showed no expression of MET and PDGFR, and less often expression of VEGFR3, while wild-type tumors expressed VEGF more often than tumors with RET or RAS mutations (Mancikova et al. 2014). More detailed analysis of TKI target genes in correlation with RET or RAS mutation status in a larger series of MTC tumors might be a useful tool to develop a more personalized strategy for TKI treatment in advanced MTC.

\section{Results of clinical trials of 'molecularly targeted' therapies}

The identification of key therapeutic molecular targets (Fig. 1) in MTC has begun to meaningfully impact clinical practice. Two multitargeted kinase inhibitors, vandetanib and cabozantinib, are now approved in the US and EU for use in advanced, progressive MTC; with additional targeted agents also showing promise or awaiting results from clinical trials (Table 1).

\section{Vandetanib}

Vandetanib is an inhibitor of RET, VEGFR-2 and -3, and EGFR, and was one of the first oral multikinase inhibitors investigated in advanced MTC patients. In a first phase 2 trial in patients with unresectable locally advanced or metastatic hereditary MTC $(n=30)$, vandetanib at an initial dose of $300 \mathrm{mg} /$ day yielded partial responses (PRs) in $20 \%$ of patients, with an additional $53 \%$ showing stable disease (SD) (Wells et al. 2010). In a second phase 2 trial, 19 patients with locally advanced or metastatic hereditary MTC received vandetanib at a dose of $100 \mathrm{mg}$ /day with similar results, with PRs in three patients (16\%) and SD in ten patients (53\%) (Robinson et al. 2010). Vandetanib was also reported to be effective in 16 children and adolescents with locally advanced or metastatic hereditary MTC in a further phase $1 / 2$ trial, with $47 \%$ PRs observed (Fox et al. 2013). On the basis of favorable outcomes in these phase 2 trials, the randomized, multicenter phase 3 ZETA drug registration trial was performed (Wells et al. 2012). Efficacy and safety of vandetanib were compared with placebo in patients with locally advanced or metastatic hereditary or sporadic MTC; $90 \%$ of the patients had sporadic or unknown disease, and $95 \%$ had metastatic disease. It is important to note that significantly progressive disease according to RECIST was not required for inclusion in the trial. 331 patients were randomly assigned (2:1) to receive vandetanib $(300 \mathrm{mg} /$ day $)(n=231)$ or placebo $(n=100)$. The study met its primary objective with median PFS of 30.5 months in the vandetanib group versus 19.3 months in the placebo group (hazard ratio 0.46 ; 95\% CI: 0.31-0.69; $P<0.001$ ), and with PRs observed in $45 \%$ of vandetanibtreated patients. The comparably long PFS of 19.3 months in the placebo group, however, shows that the ZETA trial included many patients with indolent disease.

Subgroup analysis demonstrated superiority of vandetanib over placebo treatment in all assessed subgroups, including hereditary vs sporadic/unknown disease, prior systemic therapy vs no prior therapy, calcitonin, or CEA doubling time $>24$ months vs $<24$ months. A RET mutation was present in 155 patients with sporadic disease, no RET mutation was found in 8 patients, and RET mutation status was unknown in 135 patients. Based on the small number of RET nonmutated patient tumors, subgroup analyses of PFS and objective response rates by 
RET mutation status remained inconclusive. This open question is currently being addressed in a European, observational, prospective study to evaluate the benefit/risk of vandetanib in RET mutated and nonmutated patients with symptomatic, aggressive, sporadic, unresectable, locally advanced/metastatic MTC (NCT01945762). Subgroup analysis of PFS by M918T mutation suggested that patients with M918T-mutated tumors had a higher response rate to vandetanib than patients with M918T nonmutated tumors. Overall survival analysis in the ZETA trial is hampered by the crossover study design.

Common adverse advents were diarrhea, rash, nausea, hypertension, and headache. More patients required dose reduction of vandetanib (35\%) compared with placebo (3\%). Nineteen patients developed QTc prolongation without reports of torsades de pointes. Treatment had to be discontinued because of toxicity in $12 \%$ of patients. Potentially treatment-related grade 5 lethal toxicity occurred in five patients (2\%) who were treated with vandetanib.

The U.S. Food and Drug Administration (FDA) approved vandetanib for use in MTC in 2011, followed by approval in Europe in 2012. In the US, vandetanib can only be prescribed by physicians after completion of a vandetanib Risk Evaluation and Mitigation Strategy (REMS) program because of a black box warning for QTc prolongation.

\section{Cabozantinib}

Cabozantinib (XL184) is a multitargeted kinase inhibitor most potently targeting VEGFR2, c-MET, and RET. The simultaneous inhibition of both VEGFR and c-MET is thought to reduce c-MET-driven resistance observed in the course of VEGFR-targeted TKI therapy. In a phase 1 dose escalation study (MTD of cabozantinib $140 \mathrm{mg} /$ day) in patients with advanced solid tumors including 37 MTC patients, 10 of 35 MTC patients with measurable disease (29\%) showed PRs and 15 of 37 patients had SD for at least 6 months; most patients had sporadic disease and had received prior therapy, including 16 patients with prior TKI therapy (Kurzrock et al. 2011). Based on these results, an international, double-blind, randomized, placebo-controlled phase 3 drug registration trial (EXAM) was conducted to evaluate safety and efficacy of cabozantinib vs placebo in patients with metastatic MTC (Elisei et al. 2013). In contrast to the vandetanib ZETA trial documented radiographic disease progression according to RECIST (response evaluation criteria in solid tumors) within 14 months before study entry was required. 330 patients were randomly assigned (2:1) to cabozantinib $(140 \mathrm{mg} /$ day) or placebo. $40 \%$ of patients had received prior anticancer therapy and $21 \%$ had received prior TKI treatment. Most patients (86\%) had sporadic disease; $48.2 \%$ had RET-mutated tumors (74\% M918T), 12\% had RET-nonmutated tumors, and 39\% had tumors of unknown RET mutational status. The primary end point was reached with PFS of 11.2 months in the cabozantinib group vs 4.0 months in the placebo group (hazard ratio 0.28; 95\% CI: 0.19-0.40; p<0.001). In subgroup analyses, longer PFS with cabozantinib therapy vs placebo was observed independent of patient age, previous anticancer regimens, prior TKI therapy, RET mutational status, or bone metastases at baseline. The objective response rate (ORR) was $28 \%$ (all PRs), regardless of RET mutation status. The subset of patients with RET nonmutated (44) or RET unknown tumors (41) were evaluated for RAS mutations, with 16 of 85 (19\%) found to harbor RAS mutations showing similar PR rate (31\%) and PFS (47 weeks) as patients with RET-mutated tumors (RR 32\%, PFS 60 weeks) (Sherman et al. 2013).

Common cabozantinib-associated adverse events include AST/ALT elevation, diarrhea, palmarplantar-erythrodysesthesia (hand-foot dermatitis), stomatitis, weight loss, reduced appetite, nausea, and fatigue - collectively resulting in dose reductions in 79\% and treatment discontinuation in $16 \%$ of cabozantinibtreated patients. Grade 3 or 4 adverse events were reported in $69 \%$ of patients, so overall, the toxicity of cabozantinib was considerable. Potentially therapy-related grade 5 lethal toxicity occurred in 17 patients (7.9\%) treated with cabozantinib.

Adverse event profile did not change with longterm cabozantinib therapy (Schlumberger et al. 2015). Gastrointestinal perforations, fistula development, and hemorrhage were observed in the cabozantinib group, prompting caution in patients at perceived higher risk for such events, such as patients with peptic ulcer disease, history of diverticulitis, tumor invasion of esophagus or trachea, or patients that had been treated with external beam radiation in the cervical and/or mediastinal region. Metabolic changes in the cabozantinib group included TSH elevations and hypocalcemia which need to be monitored more closely, as is the case of patients treated with any kinase inhibitor. Overall, the rate of dose reductions was high, indicating that $140 \mathrm{mg}$ was quite toxic for most patients. Evaluation of a lower starting dose $(60 \mathrm{mg} /$ day $)$ in patients with progressive, metastatic MTC is ongoing 
(EXAMINER, NCT01896479), with expert consensus currently favoring a starting dosage of $60 \mathrm{mg}$, not $140 \mathrm{mg}$, daily. Also, studies in patients with renal impairment (XL184-017) and hepatic impairment (XL184-003) are ongoing. In contrast to the vandetanib ZETA trial, patients in the placebo group were not permitted to crossover to cabozantinib in case of disease progression. Final analysis of overall survival (OS) data presented at the Annual Meeting of the American Society of Clinical Oncology in 2015 and at the International Thyroid Congress in 2015 showed longer OS of 26.6 months in the cabozantinib group as compared with 21.1 months in the placebo group, not reaching statistical significance (HR 0.85, $P=0.2409$ ). However, in the subgroup of patients with the RET M918T mutation, a statistically significantly longer OS was observed (44.3 months in the cabozantinib group vs 18.9 months in the placebo group; HR 0.6, $P=0.026$; not adjusted for multiple subgroup analyses). The RET M918T subgroup also showed the longest PFS of 13.9 months in the cabozantinib group vs 4.0 months in the placebo group, and the highest ORR of 34\% (Schlumberger et al. 2015). While it has been demonstrated that RET inhibition can result in changes in calcitonin levels independent of changes in tumor size, in the EXAM trial, correlations were observed between changes in calcitonin and CEA levels from baseline to week 12 and changes in target lesion size, suggesting that these serum tumor markers may forecast likelihood of patient anatomical benefit (Elisei et al. 2013). On the basis of these results, the FDA approved cabozantinib for the treatment of MTC in 2012 followed by approval in Europe in 2014.

\section{Sorafenib}

Sorafenib, a multitargeted kinase inhibitor targeting VEGFR, PDGFR, FGFR, c-KIT, BRAF, and RET, approved for the treatment of advanced radioiodine-refractory differentiated thyroid cancer in the USA and Europe, has also been investigated in a phase 2 trial in patients with metastatic thyroid cancers, some of whom had sporadic or hereditary MTC (Lam et al. 2010). Patients received sorafenib at $400 \mathrm{mg}$ twice daily. Out of 16 patients in the sporadic MTC group (10 of them with progressive disease within 12 months), one achieved PR (6.3\%), and 14 $(87.5 \%)$ showed SD in response to 6 months of therapy. Median PFS was 17.9 months. Accrual to the hereditary MTC group was terminated due to slow accrual. Common adverse events included diarrhea, hand-foot-skin reaction, rash, and hypertension. A decrease in calcitonin or CEA or both was observed in the majority of patients treated with sorefenib, but neither baseline levels of these two tumor markers nor the degree of tumor marker response correlated well with the degree of tumor response. In another phase 2 study in a UK population, the efficacy and toxicity of sorafenib was evaluated in 15 MTC patients. The response rate at 12 months was 25\%, PFS was 93\%, and OS was 100\% (Ahmed et al. 2011). Interestingly, PR rate doubled from 13 to $25 \%$ when evaluated at 6 vs 12 months of therapy, indicating that late responses in MTC were seen. In an off-label observational study, five patients with progressive metastatic MTC were treated with sorafenib (400 mg twice daily). Two patients showed a partial response and two patients experienced stable disease (Frank-Raue et al. 2011). In a recently published retrospective longitudinal study of 12 patients with progressive metastatic MTC, 10 patients showed stable disease (83.3\%), no PR was observed. Median PFS was 9 months (Castroneves et al. 2016). These data collectively suggest a possible role for sorafenib in the treatment of progressive, advanced MTC; however, a randomized phase 3 trial is required for rigorous evaluation of safety and efficacy of sorafenib in these patients.

\section{Sunitinib}

Sunitinib inhibits VEGFR, c-KIT, PDGFR, and RET, and has been evaluated in several small phase 2 studies in patients with advanced MTC. In a phase 2 trial in seven patients with metastatic MTC (Carr et al. 2010), patients were treated with continuous dosing of sunitinib at $37.5 \mathrm{mg} /$ day; six patients were evaluable with PRs observed in three, and SD in two. The most common toxicities included fatigue, neutropenia, hand/foot syndrome, diarrhea, and leukopenia. In another phase 2 trial, patients with advanced MTC who had evidence of disease progression within the prior 6 months were treated with sunitinib, $50 \mathrm{mg}$ daily, 4 weeks on therapy, and 2 weeks off. 25 patients were enrolled, 23 were evaluable for response. RET-activating mutations were detected in 11 of 13 analyzed tumors (8 somatic, 3 germline). PRs were achieved in 8 (35\%); 13 (57\%) had SD. PR or SD lasting greater than 24 weeks was observed in seven of nine patients with the M918T RET mutation (De Souza et al. 2010). Intermediate results were also reported from another phase 2 trial performed in France among 15 patients with progressive MTC. Two patients had PR, and seven had SD (Ravaud et al. 2010). Overall, data from phase 2 trials suggest that sunitinib also has efficacy in MTC, but it has not yet been further investigated in a phase 3 trial.

Published by Bioscientifica Ltd. 


\section{Pazopanib}

Pazopanib, another kinase inhibitor that targets VEGFR1-3, PDGFR, c-KIT, FGFR1/3/4, and RET is already approved for use in renal cell carcinoma and soft tissue sarcoma. Having previously observed a high level of clinical response from pazopanib in advanced and progressive DTC (Bible et al. 2010), a multicenter international phase 2 trial was conducted in patients with advanced MTC who had disease progression within the preceding 6 months (pazopanib $800 \mathrm{mg} /$ day) (Bible et al. 2014). Thirty-five patients were enrolled, five patients attained partial response (14.3\%) with a median PFS of 9.4 months and OS of 19.9 months. $57 \%$ of patients had no previous treatment, the other $43 \%$ had received prior therapy, including radiation therapy and systemic therapy including other TKIs such as vandetanib, cabozantinib, and sunitinib. Data from this trial further suggest that induced changes in CEA serum level, but not changes in calcitonin level, are correlated with PFS among pazopanibtreated patients. Side effects included hypertension, fatigue, diarrhea, and abnormal liver tests. Three of thirty-five patients discontinued therapy due to adverse events. One death of a study patient was considered to be potentially therapy related. Overall, it did not appear that pazopanib response varied based on prior therapies, noting that this trial was not designed or statistically powered to address this question conclusively. These data show that pazopanib also appears to have promising clinical activity in MTC, and that, like other VEGFRtargeted kinase inhibitors, pazopanib may represent a drug to be considered in MTC patients incurring disease progression despite prior treatment with MTC-approved agents. Interestingly, pazopanib is a comparably poor RET inhibitor, suggesting the possibility that RET may not necessarily be the sole or key kinase target of therapeutic relevance in MTC (Bible et al. 2014).

\section{Axitinib}

Axitinib, a VEGFR1-3 inhibitor approved for treatment of renal cell carcinoma, was evaluated in a phase 2 trial (axitinib $5 \mathrm{mg}$ twice daily) with 60 patients with advanced thyroid cancer of any histology, including 11 MTC patients. Two patients attained PR and three SD (Cohen et al. 2008). More recently, a second phase 2 trial in patients with metastatic or unresectable, locally advanced thyroid cancer was performed including six MTC patients. No responses were observed, while five attained SD (83\%)
(Locati et al. 2014). Overall, axitinib efficacy appears limited in MTC patients; however, patient numbers were too small to draw definite conclusions.

\section{Lenvatinib}

Lenvatinib, an inhibitor of VEGFR1-3, FGFR1-4, RET, KIT, and PDGFR, has recently been approved for treatment of radioiodine-refractory DTC and has also been assessed for use in patients with unresectable, progressive (within prior 12 months) MTC in a phase 2 trial (lenvatinib $24 \mathrm{mg} /$ day) (Schlumberger et al. 2016). 59 patients were enrolled; 36\% experienced PR, with comparable PR rates in patients treated with prior anti-VEGFR therapy (36\%) or not (35\%). 44\% showed SD, and median PFS was 9.0 months. RET protooncogene status did not correlate with outcomes. 58\% of the patients had received previous anticancer therapies, including conventional chemotherapy, radiotherapy, and previous anti-VEGFR therapy (including cabozantinib, sorafenib, vandetanib, motesanib, sunitinib). The most common toxicities included diarrhea, proteinuria, fatigue, hypertension, decreased appetite, nausea, decreased weight, headache, vomiting, and cough; common grade 3/4 treatment-emergent adverse events included diarrhea, hypertension, decreased appetite, fatigue, dysphagia, and increased liver enzyme levels. Although results across different clinical trials are difficult to interpret, the tumor responses observed for lenvatinib in this trial are encouraging in the context of reported data for other TKIs, but PFS seems similar to other agents piloted in MTC, including pazopanib.

\section{Motesanib}

Motesanib, an inhibitor of VEGFR1-3, PDGFR, and c-KIT that is not presently available clinically, was also evaluated in a phase 2 study in patients with progressive (within 6 months) or symptomatic, advanced, or metastatic MTC (Schlumberger et al. 2009). Most patients (84\%) had sporadic disease and nearly all (93\%) had metastatic disease. Most patients (76\%) had prior therapy including external beam radiation therapy (51\%) and chemotherapy (36\%). Of 91 patients treated with motesanib (125 mg/day), 2 (2\%) showed partial remission and $48 \%$ stable disease (longer than 6 months). Median PFS was 48 weeks. Most common treatment-related adverse events were diarrhea, fatigue, hypertension, and anorexia. 


\section{Imatinib}

Imatinib, an inhibitor of Bcr-Abl, PDGFR, c-KIT, and RET, was one of the first drugs to be investigated in MTC patients. In a phase 2 trial (imatinib $600 \mathrm{mg} /$ day), 15 patients with disseminated MTC were enrolled. No objective responses were observed, four patients had SD over 24 months (de Groot et al. 2007). In another open-label clinical trial of nine patients with sporadic or hereditary MTC with unresectable, progressive metastases, SD was observed in five patients lasting up to 6 months; and in one patient for up to 12 months; median PFS was 6 months (Frank-Raue et al. 2007). Overall, therapeutic efficacy of imatinib appears low in MTC patients.

\section{Everolimus}

Everolimus is an mTOR inhibitor approved for treatment of neuroendocrine tumors and renal cell carcinoma. Given that RET and RAS activate the PI3K/AKT/mTOR pathway, a phase 2 trial was conducted in patients with progressive (in the 12 months before therapy) metastatic or inoperable MTC (Schneider et al. 2015). Seven patients were enrolled (everolimus $10 \mathrm{mg} /$ day); five (71\%) showed SD, lasting longer than 6 months in four. Median PFS was 33 weeks and OS 30 weeks. No objective responses were observed. In another phase 2 trial, 38 patients with advanced thyroid cancer of any histology were treated with everolimus (10 mg/day) including nine patients with MTC that all showed stable disease without any objective responses (Lim et al. 2013). The combination of RET-specific kinase inhibitors with mTOR inhibitors might be an interesting dual targeting strategy, but awaits rigorous examination in clinical trials. Recently, promising data were reported from a phase 2 trial in patients with progressive, advanced thyroid cancer that received sorafenib ( $800 \mathrm{mg} /$ day) in combination with everolimus (5 mg/day), including 10 MTC patients with PRs in 4 patients (40\%) and SD in 4 patients (40\%) (Sherman et al. 2015).

\section{Tipifarnib}

Based on the detection of RAS mutations in a significant subset of RET wild-type MTC, targeting of the RAS pathway through the use of inhibitors of RAS farnelyzation, the main post-translational modification of the RAS protein, has been studied. In particular, there has been a report of apparently favorable single-agent effects of the farnesyl transferase inhibitor BMS-214662 in stabilizing disease and lowering calcitonin levels in MTC patients (Papadimitrakopoulou et al. 2005). Moreover, treatment of a patient with sporadic
MTC with a combination of sorefenib and the RAS farnelyzation inhibitor tipifarnib resulted in a sustained PR (Hong et al. 2008). In a phase 1 trial, 13 patients with MTC were treated with this combination of sorafenib and tipifarnib, 8 harboring RET mutations, but with unknown RAS mutational status. PR rate was 38\%, and SD of at least 6 months was 31\% (Hong et al. 2011). Toxicities were mainly rash, hand/foot skin reaction, neuropathy, fatigue, hypertension, anorexia, and diarrhoea. Tipifarnib as single agent is currently being investigated in a phase 2 trial in HRAS-mutated tumors, including MTC (NCT02383927).

\section{Targeted therapies in development}

Several other targeted therapies are awaiting clinical trial results. Nintedanib (BIBF1120), targeting VEGFR1-3, FGFR1-3, PDGFR $\alpha / \beta$, as well as RET, is being evaluated in a phase 2 trial as second-line therapy for patients with DTC or MTC progressing after first-line therapy (documented progression within 12 months) (NCT01788982). Another phase 2 trial is ongoing comparing the efficacy and safety of anlotinib, a multitargeted kinase inhibitor of VEGFR2, 3, PDGFR $\beta$, and c-Kit, in MTC patients (NCT02586350). As a highly potent inhibitor of RET kinase, the multikinase (BCRABL, VEGFR, PDGFR, KIT, FGFR, FLT3) inhibitor ponatinib, is being evaluated in another phase 2 trial in locally advanced or metastatic MTC patients (NCT01838642). However, significant toxicity, in particular high rates of arterial thrombotic events, was reported in a clinical trial in CML (Cortes et al. 2013). Combination treatment of vandetanib and bortezomib, a proteasome inhibitor, is studied in solid tumors with a focus on advanced MTC (NCT00923247). A phase 2 study is planned to evaluate regorafenib, an inhibitor of multiple kinases including VEGFR, TIE2, KIT, RET, RAF-1, BRAF, PDGFR, and FGFR, as second- or third-line therapy in metastatic, progressive (within 6 months) MTC (NCT02657551). Safety and efficacy of sulfatinib, a selective inhibitor of VEGFR and FGFR1, is also to be studied in a phase 2 trial in progressive, advanced thyroid cancer patients, including MTC (NCT02614495). Results are also awaited from a phase 2 trial evaluating the histone deacetylase inhibitor LBH589 in metastatic DTC as well as MTC (NCT01013597).

\section{Cytotoxic chemotherapy}

Before the advent of kinase inhibitors, cytotoxic chemotherapy was also found of some therapeutic utility in advanced MTC. In particular, dacarbazine-based therapy has shown activity in MTC. These data are often now forgotten,

Published by Bioscientifica Ltd 
yet cytotoxic chemotherapy still has utility in at least a subset of MTC patients. A recent study of nine MTC patients treated with the combination of cyclophosphamide, vincristine, and dacarbazine led to one PR and median PFS of 13.6 months (Deutschbein et al. 2011). A smaller study of the same regimen led to two PRs among seven MTC patients, with one patient attaining benefit lasting over 2 years (Wu et al. 1994). Another study of 20 patients alternating doxorubicin and 5-fluorouracil/streptozocin/ dacarbazine yielded three PRs (15\%), with median PFS longer than the reported 25 month mean follow-up duration (Nocera et al. 2000). A smaller study of five MTC patients treated with dacarbazine and 5-fluorouracil yielded three PRs (Orlandi et al. 1994); moreover, a complete response was also reported using the same regimen in a single MTC patient (Petursson 1988). A PR was additionally reported in a single patient in response to temozolomide combined with capecitabine (oral prodrugs of dacarbazine and 5-fluorouracil, respectively) (Lacin et al. 2015). Collectively, these data are a reminder that novel cytotoxic approaches may be worthy of assessment also in MTC.

\section{Clinical implications and future outlook}

Evolving knowledge has defined a central role of activating and oncogenic RET mutations in MTC. Constitutive and unopposed RET activation in turn activates downstream growth and proliferation pathways involving RAS-RAFMEK-ERK, PI3K-AKT-mTOR, and JAK/STAT. Several multitargeted kinase inhibitors - many with significant anti-RET activity - have been evaluated in phase 1,2, and 3 trials and found efficacious in MTC, with vandetanib and cabozantinib now approved by the U.S. FDA and EU EMA, significantly changing the management of patients with advanced, progressive MTC. However, questions of which drug is more likely effective in which contexts in advanced MTC cannot be answered on the basis of available data from completed trials (including the ZETA and EXAM randomized phase 3 trials), as comparative efficacy studies have yet to be conducted. While the EXAM trial required radiographic disease progression within 14 months, the ZETA trial did not [as reflected in the significantly longer PFS in the ZETA placebo group (19.3 months) as compared with the EXAM placebo group (4 months)]. Analysis of improvement in OS for vandetanib is moreover hampered by the crossover design of the ZETA trial, in contrast to the EXAM trial wherein crossover was not permitted. Moreover, in either trial, off-label crossover upon progression could also occur, hence additionally confounding interpretation of survival analyses that are still maturing but that have not yet convincingly demonstrated survival benefits.

With respect to personalization of MTC therapy, OS was significantly longer in EXAM trial patients with tumors bearing the RET M918T mutation. These data may imply that genetic analysis of tumor tissue has potential to affect therapeutic personalization in MTC. However, tumor samples are not always available, re-biopsy of metastases is not always feasible, and/or ethically justifiable and affordable. Additionally, RET mutational analysis results can vary between primary tumor and different sites of metastases. Much additional work is thus required in aspiring to meaningful therapy personalization based upon tumor characteristics in MTC.

It is also critical to recognize that, despite the approval of two drugs for the treatment of metastatic MTC, the majority of MTC patients do not need systemic therapy - and that its application in many patient has potential to cause more harm than good. Based on the current knowledge, there is no evidence that early initiation of therapy offers any meaningful prospect of higher therapeutic efficacy compared with starting therapy at a later stage, when the disease has radiographically progressed to a high tumor load. Kinase-inhibitor therapy can moreover reduce quality of life, and treatment-related mortality of $1-2 \%$ has also to be weighed against lack of complete remissions/curative outcomes, and uncertain OS enhancement. Therefore, the use of molecularly targeted therapies should currently be limited to patients with progressive, metastatic, and imminently threatening disease, in setting also wherein other palliative and lesstoxic treatment strategies are not feasible and whereby a 'watch and wait' strategy can no longer be justified due to presence of disease that threatens vital structures, produces symptoms, and/or is found rapidly progressive.

The drug of first choice in any individual patient should be decided using a patient-centered approach, taking into consideration medical history, findings on physical examination, current medication, laboratory results, comorbidities, EKG results, risk of bleeding and/or fistula development, and tumor characteristics. As advanced, progressive MTC is a rare and complex disease, a multidisciplinary approach centered in specialized centers providing interdisciplinary expertise in the individualization of available therapeutic options is preferred. Despite the availability of two approved drugs, and the possibility of off-label use of a series of other TKIs, all patients should be evaluated for participation in clinical trials, whenever feasible.

With yet further improved understanding of key molecular events in the pathogenesis of MTC, the future

Published by Bioscientifica Ltd 
offers promise for additional therapeutic progress and improved outcomes in advanced, progressive MTC. Combinations of novel agents (with each other and/or with cytotoxic chemotherapy) and multimodal approaches may improve upon monotherapy outcomes. Potentially promising strategies for combinatorial treatment include dual targeting of central signaling pathways, such as RET and PI3K/AKT (or RAS) pathways, in hopes of simultaneously downregulating often simultaneously activated signaling pathways. Such multipronged therapy has potential to thereby address parallel 'escape' pathways otherwise with potential to produce resistance to monotherapy. Finally, it will be exciting also to see results of clinical trials of immunotherapy in MTC. It is our aspiration that more detailed understanding of resistance mechanisms and identification of predictive biomarkers will ultimately guide development of more effective targeted therapies in a more individualized manner.

\section{Declaration of interest}

Christine Spitzweg has received honoraria for advisory boards or lectures from Novartis, AstraZeneca, Eisai, Swedish Orphan Biovitrum, and Bayer. The authors declare that there is no conflict of interest that could be perceived as prejudicing the impartiality of this review.

\section{Funding}

This work was supported by grants from the Deutsche Forschungsgemeinschaft SFB 824 (project C08) and SP 581/6-1 and SP581/6-2 (SPP 1629) to C. Spitzweg.

\section{Author contribution statement}

All authors contributed to the concept of the review, did the literature searches, and wrote the paper. Christine Spitzweg and John Morris focused on the molecular pathogenesis of medullary thyroid cancer and clinical trials of molecular targeted therapies, and Keith C Bible focused on clinical trials of molecular targeted therapies and future outlooks for treatment. Christine Spitzweg and Keith Bible created the figure and table.

\section{References}

Ahmed M, Barbachano Y, Riddell A, Hickey J, Newbold KL, Viros A, Harrington KJ, Marais R \& Nutting CM 2011 Analysis of the efficacy and toxicity of sorafenib in thyroid cancer: a phase II study in a UK based population. European Journal of Endocrinology 165 315-322. (doi:10.1530/EJE-11-0129)

Bible KC, Suman VJ, Molina JR, Smallridge RC, Maples WJ, Menefee ME, Rubin J, Sideras K, Morris JC 3rd, McIver B, et al. 2010 Efficacy of pazopanib in progressive, radioiodine-refractory, metastatic differentiated thyroid cancers: results of a phase 2 consortium study. Lancet Oncology 11 962-972. (doi:10.1016/S1470-2045(10)70203-5)

Bible KC, Suman VJ, Molina JR, Smallridge RC, Maples WJ, Menefee ME, Rubin J, Karlin N, Sideras K, Morris JC 3rd, et al. 2014 A multicenter phase 2 trial of pazopanib in metastatic and progressive medullary thyroid carcinoma: MC057H. Journal of Clinical Endocrinology \& Metabolism 99 1687-1693. (doi:10.1210/jc.2013-3713)
Cabanillas ME, Hu MI \& Jimenez C 2014 Medullary thyroid cancer in the era of tyrosine kinase inhibitors: to treat or not to treat-and with which drug-those are the questions. Journal of Clinical Endocrinology \& Metabolism 99 4390-4396. (doi:10.1210/jc.2014-2811)

Carr LL, Mankoff DA, Goulart BH, Eaton KD, Capell PT, Kell EM, Bauman JE \& Martins RG 2010 Phase II study of daily sunitinib in FDG-PET-positive, iodine-refractory differentiated thyroid cancer and metastatic medullary carcinoma of the thyroid with functional imaging correlation. Clinical Cancer Research 16 5260-5268. (doi:10.1158/1078-0432.CCR-10-0994)

Castroneves LA, Negrao MV, Freitas RM, Papadia C, Lima Jr JV, Fukushima J, Simao EF, Kulcsar MA, Tavares M, Jorge AA, et al. 2016 Sorafenib for the treatment of progressive metastatic medullary thyroid cancer: efficacy and safety analysis. Thyroid 26 414-419. (doi:10.1089/thy.2015.0334)

Chernock RD \& Hagemann IS 2015 Molecular pathology of hereditary and sporadic medullary thyroid carcinomas. American Journal of Clinical Pathology 143 768-777. (doi:10.1309/ AJCPHWACTTUYJ7DD)

Cohen EE, Rosen LS, Vokes EE, Kies MS, Forastiere AA, Worden FP, Kane MA, Sherman E, Kim S, Bycott P, et al. 2008 Axitinib is an active treatment for all histologic subtypes of advanced thyroid cancer: results from a phase II study. Journal of Clinical Oncology 26 4708-4713. (doi:10.1200/JCO.2007.15.9566)

Cortes JE, Kim DW, Pinilla-Ibarz J, le Coutre P, Paquette R, Chuah C, Nicolini FE, Apperley JF, Khoury HJ, Talpaz M, et al. 2013 A phase 2 trial of ponatinib in Philadelphia chromosome-positive leukemias. New England Journal of Medicine 369 1783-1796. (doi:10.1056/ NEJMoa1306494)

de Groot JW, Zonnenberg BA, van Ufford-Mannesse PQ, de Vries MM, Links TP, Lips CJ \& Voest EE 2007 A phase II trial of imatinib therapy for metastatic medullary thyroid carcinoma. Journal of Clinical Endocrinology \& Metabolism 92 3466-3469. (doi:10.1210/jc.2007-0649)

De Souza JA, Busaidy N, Zimrin A, Seiwert TY, Villaflor VM, Poluru KB, Reddy PL, Nam J, Vokes EE \& Cohen EE 2010 Phase II trial of suntinib in medullary thyroid cancer (MTC). Journal of Clinical Oncology 28 (Supplement) Abstract 5504.

Deutschbein T, Matuszczyk A, Moeller LC, Unger N, Yuece A, Lahner H, Mann K \& Petersenn S 2011 Treatment of advanced medullary thyroid carcinoma with a combination of cyclophosphamide, vincristine, and dacarbazine: a single-center experience. Experimental and Clinical Endocrinology \& Diabetes 119 540-543. (doi:10.1055/S-0031-1279704)

Elisei R, Schlumberger MJ, Muller SP, Schoffski P, Brose MS, Shah MH, Licitra L, Jarzab B, Medvedev V, Kreissl MC, et al. 2013 Cabozantinib in progressive medullary thyroid cancer. Journal of Clinical Oncology 31 3639-3646. (doi:10.1200/JCO.2012.48.4659)

Fox E, Widemann BC, Chuk MK, Marcus L, Aikin A, Whitcomb PO, Merino MJ, Lodish M, Dombi E, Steinberg SM, et al. 2013 Vandetanib in children and adolescents with multiple endocrine neoplasia type 2B associated medullary thyroid carcinoma. Clinical Cancer Research 19 4239-4248. (doi:10.1158/1078-0432.CCR-13-0071)

Frank-Raue K, Fabel M, Delorme S, Haberkorn U \& Raue F 2007 Efficacy of imatinib mesylate in advanced medullary thyroid carcinoma. European Journal of Endocrinology 157 215-220. (doi:10.1530/EJE-06-0695)

Frank-Raue K, Ganten M, Kreissl MC \& Raue F 2011 Rapid response to sorafenib in metastatic medullary thyroid carcinoma. Experimental and Clinical Endocrinology \& Diabetes 119 151-155. (doi:10.1055/S-0030-1262836)

Hadoux J, Pacini F, Tuttle RM \& Schlumberger M 2016 Management of advanced medullary thyroid cancer. Lancet. Diabetes \& Endocrinology 4 64-71. (doi:10.1016/S2213-8587(15)00337-X)

Hong D, Ye L, Gagel R, Chintala L, El Naggar AK, Wright J \& Kurzrock R 2008 Medullary thyroid cancer: targeting the RET kinase pathway with sorafenib/tipifarnib. Molecular Cancer Therapeutics 7 1001-1006. (doi:10.1158/1535-7163.MCT-07-2422) 
Hong DS, Cabanillas ME, Wheler J, Naing A, Tsimberidou AM, Ye L, Busaidy NL, Waguespack SG, Hernandez M, El Naggar AK, et al. 2011 Inhibition of the Ras/Raf/MEK/ERK and RET kinase pathways with the combination of the multikinase inhibitor sorafenib and the farnesyltransferase inhibitor tipifarnib in medullary and differentiated thyroid malignancies. Journal of Clinical Endocrinology \& Metabolism 96 997-1005. (doi:10.1210/jc.2010-1899)

Ji JH, Oh YL, Hong M, Yun JW, Lee HW, Kim D, Ji Y, Kim DH, Park WY, Shin HT, et al. 2015 Identification of driving ALK fusion genes and genomic landscape of medullary thyroid cancer. PLoS Genetics 11 e1005467. (doi:10.1371/journal.pgen.1005467)

Kurzrock R, Sherman SI, Ball DW, Forastiere AA, Cohen RB, Mehra R, Pfister DG, Cohen EE, Janisch L, Nauling F, et al. 2011 Activity of XL184 (Cabozantinib), an oral tyrosine kinase inhibitor, in patients with medullary thyroid cancer. Journal of Clinical Oncology 292660 2666. (doi:10.1200/JCO.2010.32.4145)

Lacin S, Esin E, Karakas Y \& Yalcin S 2015 Metastatic medullary thyroid cancer: a dramatic response to a systemic chemotherapy (temozolomide and capecitabine) regimen. Onco Targets and Therapy 8 1039-1042. (doi:10.2147/OTT)

Lam ET, Ringel MD, Kloos RT, Prior TW, Knopp MV, Liang J, Sammet S, Hall NC, Wakely PE Jr, Vasko VV, et al. 2010 Phase II clinical trial of sorafenib in metastatic medullary thyroid cancer. Journal of Clinical Oncology 28 2323-2330. (doi:10.1200/JCO.2009.25.0068)

Lim SM, Chang H, Yoon MJ, Hong YK, Kim H, Chung WY, Park CS, Nam KH, Kang SW, Kim MK, et al. 2013 A multicenter, phase II trial of everolimus in locally advanced or metastatic thyroid cancer of all histologic subtypes. Annals of Oncology 24 3089-3094. (doi:10.1093/ annonc/mdt379)

Locati LD, Licitra L, Agate L, Ou SH, Boucher A, Jarzab B, Qin S, Kane MA, Wirth LJ, Chen C, et al. 2014 Treatment of advanced thyroid cancer with axitinib: Phase 2 study with pharmacokinetic/ pharmacodynamic and quality-of-life assessments. Cancer 120 2694-2703. (doi:10.1002/cncr.28766)

Mancikova V, Inglada-Perez L, Curras-Freixes M, de Cubas AA, Gomez A, Leton R, Kersten I, Leandro-Garcia LJ, Comino-Mendez I, ApellanizRuiz M, et al. 2014 VEGF, VEGFR3, and PDGFRB protein expression is influenced by RAS mutations in medullary thyroid carcinoma. Thyroid 24 1251-1255. (doi:10.1089/thy.2013.0579)

Moura MM, Cavaco BM \& Leite V 2015 RAS proto-oncogene in medullary thyroid carcinoma. Endocrine-Related Cancer 22 R235-R252.

Mulligan LM 2014 RET revisited: expanding the oncogenic portfolio. Nature Reviews. Cancer 14 173-186. (doi:10.1038/nrc3680)

Nocera M, Baudin E, Pellegriti G, Cailleux AF, Mechelany-Corone C \& Schlumberger M 2000 Treatment of advanced medullary thyroid cancer with an alternating combination of doxorubicin-streptozocin and 5 FU-dacarbazine. Groupe d'Etude des Tumeurs a Calcitonine (GETC). British Journal of Cancer 83 715-718. (doi:10.1054/bjoc.2000.1314)

Orlandi F, Caraci P, Berruti A, Puligheddu B, Pivano G, Dogliotti L \& Angeli A 1994 Chemotherapy with dacarbazine and 5-fluorouracil in advanced medullary thyroid cancer. Annals of Oncology 5 763-765.

Papadimitrakopoulou V, Agelaki S, Tran HT, Kies M, Gagel R, Zinner R, Kim E, Ayers G, Wright J \& Khuri F 2005 Phase I study of the farnesyltransferase inhibitor BMS-214662 given weekly in patients with solid tumors. Clinical Cancer Research 11 4151-4159. (doi:10.1158/1078-0432.CCR-04-1659)

Petursson SR 1988 Metastatic medullary thyroid carcinoma. Complete response to combination chemotherapy with dacarbazine and 5-fluorouracil. Cancer 62 1899-1903. (doi:10.1002/10970142(19881101)62:9<1899::aid-cncr2820620905>3.0.co;2-c)

Ravaud A, de la Fouchardiere C, Asselineau J, Delord JP, Do Cao C, Niccoli P, Rodien P, Klein M \& Catargi B 2010 Efficacy of sunitinib in advanced medullary thyroid carcinoma: intermediate results of phase II THYSU. Oncologist 15 212-213. (doi:10.1634/theoncologist.2009-0303)

Robinson BG, Paz-Ares L, Krebs A, Vasselli J \& Haddad R 2010 Vandetanib (100 mg) in patients with locally advanced or metastatic hereditary medullary thyroid cancer. Journal of Clinical Endocrinology \& Metabolism 95 2664-2671. (doi:10.1210/jc.2009-2461)

Rodriguez-Antona C, Munoz-Repeto I, Inglada-Perez L, de Cubas AA, Mancikova V, Canamero M, Maliszewska A, Gomez A, Leton R, Leandro-Garcia LJ, et al. 2013 Influence of RET mutations on the expression of tyrosine kinases in medullary thyroid carcinoma. Endocrine-Related Cancer 20 611-619. (doi:10.1530/ERC-12-0316)

Schlumberger MJ, Elisei R, Bastholt L, Wirth LJ, Martins RG, Locati LD, Jarzab B, Pacini F, Daumerie C, Droz JP, et al. 2009 Phase II study of safety and efficacy of motesanib in patients with progressive or symptomatic, advanced or metastatic medullary thyroid cancer. Journal of Clinical Oncology 27 3794-3801. (doi:10.1200/JCO.2008.18.7815)

Schlumberger M, Elisei R, Müller S, Schöffski P, Brose MS, Shah MH, Licitra L, Jarzab B, Medvedev V, Kreissl M, et al. 2015 Final overall survival analysis of EXAM, an international, double-blind, randomized, placebo-controlled phase III trial of cabozantinib (Cabo) in medullary thyroid carcinoma (MTC) patients with documented RECIST progression at baseline. Journal of Clinical Oncology 33 (Supplement) Abstract 6012.

Schlumberger M, Jarzab B, Cabanillas ME, Robinson B, Pacini F, Ball DW, McCaffrey J, Newbold K, Allison R, Martins RG, et al. 2016 A phase II trial of the multitargeted tyrosine kinase inhibitor lenvatinib (E7080) in advanced medullary thyroid cancer. Clinical Cancer Research 22 44-53. (doi:10.1158/1078-0432.CCR-15-1127)

Schneider TC, de Wit D, Links TP, van Erp NP, van der Hoeven JJ, Gelderblom H, van Wezel T, van Eijk R, Morreau H, Guchelaar HJ, et al. 2015 Beneficial effects of the mTOR inhibitor everolimus in patients with advanced medullary thyroid carcinoma: subgroup results of a phase II trial. International Journal of Endocrinology 2015348124. (doi:10.1155/2015/348124)

Sherman E, Cohen EE, Schoffski P, Elisei R, Schlumberger M, Wirth LJ, Mangeshkar M, Aftab DT, Clary DO \& Brose MS 2013 Efficacy of cabozantinib (Cabo) in medullary thyroid cancer (MTC) patients with RAS or RET mutations: results from a phase III study. Journal of Clinical Oncology 31 (Supplement) Abstract 6000.

Sherman E, Ho AL, Fury MG, Baxi SS, Dunn L, Lee JS, Lipson BL \& Pfister D 2015 Combination of everolimus and sorafenib in the treatment of thyroid cancer: update on phase II study. Journal of Clinical Oncology 33 (Supplement) Abstract 6069.

Wells SA Jr, Gosnell JE, Gagel RF, Moley J, Pfister D, Sosa JA, Skinner M, Krebs A, Vasselli J \& Schlumberger M 2010 Vandetanib for the treatment of patients with locally advanced or metastatic hereditary medullary thyroid cancer. Journal of Clinical Oncology 28 767-772. (doi:10.1200/JCO.2009.23.6604)

Wells SA Jr, Robinson BG, Gagel RF, Dralle H, Fagin JA, Santoro M, Baudin E, Elisei R, Jarzab B, Vasselli JR, et al. 2012 Vandetanib in patients with locally advanced or metastatic medullary thyroid cancer: a randomized, double-blind phase III trial. Journal of Clinical Oncology 30 134-141. (doi:10.1200/JCO.2011.35.5040)

Wells SA Jr, Asa SL, Dralle H, Elisei R, Evans DB, Gagel RF, Lee N, Machens A, Moley JF, Pacini F, et al. 2015 Revised American Thyroid Association guidelines for the management of medullary thyroid carcinoma. Thyroid 25 567-610. (doi:10.1089/thy.2014.0335)

Wu LT, Averbuch SD, Ball DW, de Bustros A, Baylin SB \& McGuire WP 3rd 1994 Treatment of advanced medullary thyroid carcinoma with a combination of cyclophosphamide, vincristine, and dacarbazine. Cancer 73 432-436. (doi:10.1002/1097-0142(19940115)73:2<432::aidcncr2820730231>3.0.co;2-k)

Received in final form 6 May 2016

Accepted 16 May 2016

Accepted Preprint published online 16 May 2016 